\title{
Determinants of Satisfaction and Proper Management of Aged Population in Chapai- Nawabgonj District in Bangladesh: Multivariate Approach
}

ISSN: 2311-8636 (Print) ISSN: 2312-2021 (Online)

Licensed:

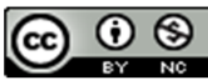

Source of Support: Nil

No Conflict of Interest: Declared

Email for correspondence: szbabu1978@gmail.com

\section{Md. Shamsuzzaman}

Assistant Regional Director, Bangladesh Open University, BANGLADESH

\section{ABSTRACT}

Improving the ability of the satisfaction and proper management to reach the aged population is important for health and essential to mitigate the income erosion consequences of ill health in Bangladesh. This study examined the satisfaction and proper management of the elderly of some identified disadvantages of aged populations; including the effect of poverty-focused nongovernmental development interventions. The objective of the study is to determine the more influential factors that are affecting the health status and living arrangements of the elderly. The data were collected by direct interview method from Chapai-Nawabgonj District, Bangladesh. The chi-square test and logistic regression model were used to fulfill the objective of this study. The results of this study reveal that among literate the majority percent aged population has at least primary education and slightly over half of them have secondary level education. The majority of the elderly people are low income, economically dependent, living with married children. Also, they are unhealthy to suffer from different kinds of illnesses like Lame, Gastric, Blood pressure, Paralysis, Diabetics, etc. A large number of people is taking treatment from M.B.B.S, and a small portion of people are taking treatment from Homeopathic and Ayurvedic physician. Despite their suffering, most of them do not get the proper care. Television, Newspaper, monthly income-expenditure, family member, and educational status are associated with the satisfaction of elderly people. The logistic regression model exposed that serious operation and proper management are the most major significant factors effects satisfaction. It also exposed that mental torture, a different shelter for the elderly are major significant factors effects proper management. The paper concludes by emphasizing the importance of enhancing local capacities to determine whether self-treatment is indicated, to investigate socio-economic background, or in cases where satisfaction and proper management is sought, to judge provider competence and evaluate whether basic needs are justified. The provision of pharmaceutical training to the full spectrum of satisfied providers is also recommended.

Keywords: Satisfaction, Proper Management, Aged Population, Logistic regression analysis 


\section{INTRODUCTION}

Bangladesh, the seventh largest (152.51millions in 2011) and one of the most densely populated countries (1015 persons per sq. $\mathrm{km}$ ) in the world has started to experience another emerging issue of population ageing in its highly vulnerable population and development context (Population \& Housing Census Report 2011). In Bangladesh, the statistical data represent that from the year 1974-2001 the number of aged populations has increased from 1.38 million to 6.05 million and 7.59 million of the total population are aged (BBS, 2003). Population ageing in Bangladesh is viewed as natural outcome of demographic transition from high fertility and mortality to low fertility and mortality. Until the year 1961, the sequence of high birth rate followed by high death rate kept the proportion of population aged 60 years and above at a low level. In the near future virtually, all countries will face population ageing, although at varying levels of intensity and in different time frames. In the recent years steady decline in birth rate accelerated the ageing process. It is likely to reach $9.1 \%$ in 2010, (Hossain, 1998) and in terms absolute number elderly person would be $13.3 \%$ million in 2010 .

Ageing population creates problems in every sector. In economic area it creates problems on pension scheme, savings, retirement, employment etc. In political reason retards to change leadership. In development countries elderly people is a social problem since many years ago but developing countries it is new problem. The statistical data represent that in Bangladesh from the year 1974 to 2001 the number of elderly populations has increased from 1.38 million to 6.05 million and at present in Bangladesh 7.5 million of the total population are elderly. It is expected that by 2021 the number of elderly will be $7.2 \%$ of the total population (Kabir, 1995), about 5.05 million elderly people are living in rural areas in Bangladesh and among them 2.305 million are elderly women (BBS, 2000). Population ageing is a world-wide phenomenon, which is mainly attributed to declining fertility, mortality and improved public health interventions. In 2000, the world-wide population of persons aged 65 years and above in project to increase from $6.9 \%$ to $12.0 \%$ world-wide from $15.5 \%$ to $24.35 \%$ in Europe, from $12.6 \%$ to $20.3 \%$ in North America, from $6.0 \%$ to $12.0 \%$ in Asia, from $5.5 \%$ to $11.6 \%$ in Latin America and from $2.9 \%$ to $3.7 \%$ in Sub-Saharan Africa (Goulding 2003).During the many years of successful family planning and public health programs that have changed the population growth of the country and demographic transition that has occurred, is enviably the outcome of socio-economic transformations through the process of development underway in the country (Strong, 1992). Development process not only has changed the demographic phenomena but also has changed life style, values, outlook of the young population, and roles and functions of family and community and thus overall change the society.

Rural old people are more in Bangladesh than urban. They are fully dependent of their own land property and sons. But traditional joint family pattern has being changed. On the other hand, social security system does not develop in rural area. Though some security systems are available for service holder people is very few in rural areas. Once average land was standard level of rural people but now maximum village people are landless. So, they are not satisfied about their needs. From the overall situation of old age people of Bangladesh by considering the basic characteristics of old people especially rural aged people of the country, it is realized a dangerous picture. In this circumstance elderly people of rural Bangladesh suffering from mental torture, permanent illness and physically depression (Cain, 1991). 
The ageing of population is a global phenomenon. Aged populations have received scant attention all over the world. The issues related to ageing problem are of great concern not only to the developed countries but also in developing ones. A number of countries will have higher percentages of aged in the year 2020; Japan; 31.1 percent, Singapore; 23.7 percent, Australia; 21.1 percent, New-Zealand; 20.2 percent and Republic of Korea; 18.6 percent (UN, 1998). Ageing is one of the emerging problems in Bangladesh. This problem has been gradually increasing with its far-reaching consequences. The aged population in Bangladesh in 1990 was 5.2 million (about 5 percent of the total population). This number will reach 14.6 million (about 9 percent of the total population) by the year 2050.Thus, the living and proper arrangements of the elderly in view of demographic change and socioeconomic transformation taking place in the country and also to explore the current situation and future trend of population ageing under the changing condition, proper investigation is firmly needed. This study is provided on that regarding matter. The aim of these study is to understand the inherent peculiarities about satisfaction and proper management of aged population.

\section{Data Source And Methodology}

The study based on primary data and the data were extracted from Chapai-Nawabgonj District, Bangladesh using purposive sampling. These data collect by questionnaire methods and the questionnaire method is handled by specially trained data collectors. Finally, we collect data from 200 aged population.

\section{Outcome variable}

The research study used preliminary data including the life history, proper management and satisfaction of aged population using purposive sample. All aged population were assessed for knowledge and awareness by asking if they had proper management and satisfaction.

\section{Predictor variables}

Most of the independent variables in this study have been considered based on previous literature reviews (Aklimunnessa K et al. 2007, Schuler SR 2008, Awan Afiaz et al. 2020). The socio-demographic factors were selected based on prior literature, pre-analysis and the theoretical framework (Awan Afiaz et al. 2020). The selected socio-demographic factors were respondent's current age (in years); place of residence (urban, rural); respondent's educational level (no education, primary, secondary, higher); Well-balance diet during pregnancy (Yes, No); BMI (Under weight, healthy weight and over weight); respondent's age at marriage (in years); and respondent's current working status (No and Yes).

\section{Statistical analysis}

The present study was carried out in two steps using a Chi-square test and a machine learning approach. In the first steps Chi-square test is used to know the association between some selected socio-economic variables and proper management and satisfaction was measured across the respondents. The second step was binary logistic regression model in addition to individual predictor variables and their impact on the likelihood of proper management and satisfaction of aged population (Fox 1985, D. R. Cox 1958, D. R. Cox 1974). This two-step method can be thought to be a simpler version of the Hosmer-Lemeshow goodness of fit (Jonathan Bartlett, 2014) using SPSS 16 was all statistical analysis. 


\section{TREND IN INTENSITY OF AgEING AND FORECASTING}

In Bangladesh, like many developing countries population ages 60 and over have been arbitrarily considered to be the aged or the elderly population. The population of Bangladesh has already (in census 2001) reached the mark of millions in which the share or the aged population is 7.8 million. A recent projection shows that the population of Bangladesh will be about 142.5 million in 2005 based on the estimated growth rate for the period 1991-2001. Now Bangladesh is one of the twenty developing countries with largest number of elderly populations.

According to census report 1974 the number of elderly populations was 4.06 million, which were 5.68 of the total population. Such number becomes 4.9 million in 1981, 5.7 million in 1991, the percentage being 5.63 and 5.63 respectively. This is increase in future. By 2025 Bangladesh along four other Asian countries will account for about half of the world's total elderly population. The UN projection suggests that by 2025 the elderly population of Bangladesh will be 16.2 million and by 2050 it will rise to 42.8 million which will be little over 9 percent \& 20 percent respectively of the total population. The rapidly increasing population is a new and important group in terms of social, economic and changing cultural context.

Table 1: Population projection and percentages of elderly of Bangladesh during the period 1980-2020.

\begin{tabular}{|c|c|c|}
\hline Year & Total population of Bangladesh & $\begin{array}{c}\text { Percentage of elderly people above 60 in } \\
\text { Bangladesh }\end{array}$ \\
\hline 1980 & 88221 & 5.28 \\
\hline 1985 & 99373 & 4.99 \\
\hline 1990 & 109465 & 4.87 \\
\hline 1995 & 118616 & 4.89 \\
\hline 2000 & 129155 & 5.11 \\
\hline 2005 & 140566 & 5.48 \\
\hline 2010 & 151799 & 6.05 \\
\hline 2015 & 161540 & 6.94 \\
\hline 2020 & 170194 & 8.01 \\
\hline
\end{tabular}

Source: World Population Prospects. The 2016 Revision, Vol. II=Sex and age

Table 2: Percentage of elderly people for different age groups in Bangladesh.

\begin{tabular}{|c|c|c|c|c|c|c|c|c|c|c|c|}
\hline Age Group & 1950 & 1960 & 1970 & 1980 & 1990 & 2000 & 2010 & 2020 & 2030 & 2040 & 2050 \\
\hline $60-64$ & 2.52 & 2.45 & 2.56 & 1.87 & 1.73 & 1.89 & 2.30 & 2.99 & 3.62 & 5.36 & 6.14 \\
\hline $65-69$ & 1.75 & 1.76 & 1.50 & 1.49 & 1.28 & 1.34 & 1.63 & 2.22 & 2.73 & 4.14 & 5.69 \\
\hline $70-74$ & 1.07 & 1.10 & 1.08 & 1.03 & 0.87 & 0.94 & 1.09 & 1.44 & 1.98 & 2.53 & 3.97 \\
\hline $75-79$ & 0.57 & 0.58 & 0.60 & 0.63 & 0.56 & 0.55 & 0.61 & 0.83 & 1.20 & 1.59 & 2.59 \\
\hline $80+$ & 0.24 & 0.27 & 0.33 & 0.29 & 0.42 & 0.38 & 0.43 & 0.55 & 0.79 & 1.20 & 1.76 \\
\hline Total & 6.15 & 6.16 & 6.07 & 5.27 & 4.86 & 5.10 & 6.06 & 8.03 & 10.30 & 14.80 & 20.20 \\
\hline
\end{tabular}

Source: World Population Prospects. The 2016 Revision, Vol. II=Sex and Age

It is mentioned that the elderly populations are increasing in all countries of the world including Bangladesh. Table 2 shows the distributions of elderly people by age group during the period 1950-2050 gradual this table indicates of the population, the speed of increase was more or less same from 1980 to 2000. The demographic researches for elderly are not enough in Bangladesh. This segment of the population is not addressed much like other segments of population. So, until today, elderly problem is not a prime concern in 
Bangladesh. The projected trend of elderly population in table-1 suggests after a decade server problem will occur in Bangladesh that will affect economic and health sector. It is the fact that the nature or elderly problems are not similar in developed and developing.

The ageing of Bangladesh population, until recently, has remained in its early stage. But from the above discussion it is clear that ageing is now a global problem and obviously it is a coming threat for the developing countries including Bangladesh. In Bangladesh, concern for elderly population is still low priority for the Government. This is partly due to the relatively small proportion of the elderly population. A more important factor may be the cultural perception that elderly people will be taken care of by the extended families to which they belong. Inspire of this, there is growing concern about the welfare of the elderly population and provision of appropriate are besides, and there has been little research works on the socio-economic and physical well being of the elderly and factors affecting their status in Bangladesh context (Kabir, 1999).

\section{RESULT AND Discussion}

\section{Descriptive statistics}

The distribution of aged population of their proper management and care their sociodemographic characteristics considered in the study. Although the age of respondents, educational status and family income was considered as numeric variables, it was converted into categorical variables for exploratory reasons in this study.

Table 3 represent the proper management and satisfaction of the aged population classified by various characteristics of the study population. A total of 200 respondents were interviewed, approximately $(59.5 \%),(28.0 \%)$ and $(12.5 \%)$ of the respondents were in the young-old (60-69 years), middle-old (70-79 years) and older-old ( $80+$ years) respectively. The majority of the respondents were Muslims (88.9\%) and rest of them were (11.1) others. About $67.0 \%$ respondents were currently married, $32.2 \%$ were widowed and only $0.8 \%$ was never married. Family types were almost same as nuclear family $(47.7 \%)$ and joint family $(52.3 \%)$. Among the respondents $41.4 \%$ were illiterate, $36.7 \%$ were primary and $21.9 \%$ were secondary and higher educated. Maximum respondents (88.0\%) were living someone and $12 \%$ were living alone.

Around two-third (72.3\%) of the respondents were never smoking and before smoking and not now were $14.6 \%$ and currently smoking were $13.1 \% .59 .7 \%$ respondents were normal body mass index and rest of them were $12.8 \%, 21.4 \%$ and $6.1 \%$ were thin, over weight and obese respectively. it is shown that educational status of the respondents, types of family, number of members of the family, monthly income of the family, working status of the respondents, basic needs, mental torture, who take care, older allowance, serious operation and shelter of the respondents were significantly associated with proper management and care of the aged population.

The results of logistic regression analysis are presented in Table 4 which depicts the effects of different variables on satisfaction of elderly people among different independent variables. In logistic analysis, respondent proper management, serious operation is significant and others are insignificant. Primary, and secondary and higher education the regression coefficient and odd ratio are -0.646 and 0.524 (CI for OR 0.117-2.350), -0.547 and 0.645 (CI for OR 0.101-5.786) respectively, which implies that the Respondents education 1st has insignificant negative effects and $2^{\text {nd }}$ has also insignificant negative effects on satisfaction of the elderly people. 
Table 3: Association between satisfactions of elderly people among socio-economic characteristics

\begin{tabular}{|c|c|c|c|c|}
\hline \multirow{2}{*}{$\begin{array}{l}\text { Socio-economic } \\
\text { characteristic }\end{array}$} & \multicolumn{3}{|c|}{ Satisfying about caring } & \multirow{2}{*}{$\begin{array}{l}\text { Significance level of } \\
\text { association at } 5 \%\end{array}$} \\
\hline & Yes & No & Total & \\
\hline \multicolumn{5}{|l|}{ Age of Respondents } \\
\hline $60-69$ & $114(88.4 \%)$ & $5(11.6 \%)$ & $119(100.0 \%)$ & Insignificant \\
\hline $70-79$ & $49(87.5 \%)$ & $7(12.5 \%)$ & $56(100.0 \%)$ & \\
\hline 80 and above & $19(80.0 \%)$ & $6(20.0 \%)$ & $25(100.0 \%)$ & \\
\hline \multicolumn{5}{|l|}{ Education } \\
\hline Illiterate & $95(82.6 \%)$ & $20(17.4 \%)$ & $115(100.0 \%)$ & Significant \\
\hline Primary & $35(87.5 \%)$ & $5(12.5 \%)$ & $40(100.0 \%)$ & \\
\hline $\begin{array}{l}\text { Secondary and } \\
\text { Higher }\end{array}$ & $44(97.8 \%)$ & $1(2.2 \%)$ & $45(100.0 \%)$ & \\
\hline \multicolumn{5}{|l|}{ Types of family } \\
\hline Single & $83(81.4 \%)$ & $19(18.6 \%)$ & $102(100.0 \%)$ & Significant \\
\hline Joint & $91(92.9 \%)$ & $7(7.1 \%)$ & $98(100.0 \%)$ & \\
\hline \multicolumn{5}{|l|}{ Family member } \\
\hline $0-2$ & $84(79.2 \%)$ & $22(20.8 \%)$ & $106(100.0 \%)$ & Significant \\
\hline $3-5$ & $80(95.2 \%)$ & $4(4.8 \%)$ & $84(100.0 \%)$ & \\
\hline$\geq 6$ & $10(100.0 \%)$ & $0(0.0 \%)$ & $10(100.0 \%)$ & \\
\hline \multicolumn{5}{|c|}{ Monthly family income } \\
\hline$<5000$ & $37(64.9 \%)$ & $20(35.1 \%)$ & $57(100.0 \%)$ & Significant \\
\hline$\geq 5000$ & $137(95.8 \%)$ & $6(4.2 \%)$ & $143(100.0 \%)$ & \\
\hline \multicolumn{5}{|c|}{ Monthly family expenditure } \\
\hline$<5000$ & $46(69.7 \%)$ & $20(30.3 \%)$ & $66(100.0 \%)$ & Significant \\
\hline$\geq 5000$ & $128(95.5 \%)$ & $6(4.5 \%)$ & $134(100.0 \%)$ & \\
\hline \multicolumn{5}{|l|}{ Types of home } \\
\hline Brick built & $126(94.7 \%)$ & $7(5.3 \%)$ & $133(100.0 \%)$ & Significant \\
\hline Made of mud & $48(71.6 \%)$ & $19(28.4 \%)$ & $67(100.0 \%)$ & \\
\hline \multicolumn{5}{|l|}{ Types of sanitation } \\
\hline Brick built & $104(96.3 \%)$ & $4(3.7 \%)$ & $108(100 \%)$ & Significant \\
\hline Made of mud & $70(76.1 \%)$ & $22(23.9 \%)$ & $92(100.0 \%)$ & \\
\hline \multicolumn{5}{|c|}{ Condition of electricity } \\
\hline No & $11(52.4 \%)$ & $10(47.6 \%)$ & $21(100.0 \%)$ & Significant \\
\hline Yes & $163(91.1 \%)$ & $16(8.9 \%)$ & $179(100.0 \%)$ & \\
\hline \multicolumn{5}{|l|}{ Television } \\
\hline No & $70(76.9 \%)$ & $21(23.1 \%)$ & $91(100.0 \%)$ & Significant \\
\hline Yes & $104(95.4 \%)$ & $5(4.6 \%)$ & $109(100.0 \%)$ & \\
\hline \multicolumn{5}{|l|}{ Working status } \\
\hline Daily worker & $45(75.0 \%)$ & $15(25.0 \%)$ & $60(100.0 \%)$ & Significant \\
\hline Weekly worker & $8(72.7 \%)$ & $3(27.3 \%)$ & $11(100.0 \%)$ & \\
\hline Monthly worker & $22(100.0 \%)$ & $0(0.0 \%)$ & $22(100.0 \%)$ & \\
\hline \multicolumn{5}{|l|}{ Basic needs } \\
\hline No & $35(64.8 \%)$ & $19(35.2 \%)$ & $54(100.0 \%)$ & Significant \\
\hline Yes & $139(95.2 \%)$ & $7(4.8 \%)$ & $146(100.0 \%)$ & \\
\hline \multicolumn{5}{|l|}{ Mental torture } \\
\hline Son & $11(84.6 \%)$ & $2(15.4 \%)$ & $13(100.0 \%)$ & Significant \\
\hline Son in law & $35(67.3 \%)$ & $17(32.7 \%)$ & $52(100.0 \%)$ & \\
\hline Husband & $8(100.0 \%)$ & $0(0.0 \%)$ & $8(100.0 \%)$ & \\
\hline Wife & $4(80.0 \%)$ & $1(20.0 \%)$ & $5(100.0 \%)$ & \\
\hline Neighbor & $33(94.3 \%)$ & $2(5.7 \%)$ & $35(100.0 \%)$ & \\
\hline Others & $83(95.4 \%)$ & $4(4.6 \%)$ & $87(100.0 \%)$ & \\
\hline
\end{tabular}




\begin{tabular}{|l|c|c|c|c|}
\hline Who take care & $119(94.4 \%)$ & $7(5.6 \%)$ & $126(100.0 \%)$ & Significant \\
\hline Son & $7(53.8 \%)$ & $6(46.2 \%)$ & $13(100.0 \%)$ & \\
\hline Daughter & $13(86.7 \%)$ & $2(13.3 \%)$ & $15(100.0 \%)$ & \\
\hline Husband & $35(77.8 \%)$ & $10(22.2 \%)$ & $45(100.0 \%)$ & \\
\hline Wife & $0(0.0 \%)$ & $1(100.0 \%)$ & $1(100.0 \%)$ & Significant \\
\hline Neighbor & $159(91.9 \%)$ & $14(8.1 \%)$ & $173(100.0 \%)$ & \\
\hline Older allowance & $15(55.6 \%)$ & $12(44.4 \%)$ & $27(100.0 \%)$ & Significant \\
\hline No & $144(99.3 \%)$ & $1(0.7 \%)$ & $145(100.0 \%)$ & \\
\hline Yes & $30(54.5 \%)$ & $25(45.5 \%)$ & $55(100.0 \%)$ & \\
\hline Shelter for older &
\end{tabular}

Again, the odds ratio over education is 0.524 and 0.645 times better satisfaction than reference category. From the Table 4 it is observed that the relationship is insignificant, because in the study area satisfaction does not depend on education. Types of family, for joint the regression coefficient and odd ratio is -1.976 and 0.139 (CI for OR 0.007-2.575), which implies that the types of family have insignificant negative effects on satisfaction of the elderly people. Again, the odds ratio over types of family is 0.139 times better satisfaction than reference category. From the Table 4 it is observed that the relationship is insignificant, because in the study area satisfaction does not depend on types of family. In case of quality of house, for made of mud the regression coefficient and odd ratio is 0.328 and 1.389 (CI for OR 0.114-16.921), which implies that the quality of house have insignificant positive effects on satisfaction of the elderly people. Again the odds ratio over quality of house is 1.389 times better satisfaction than reference category. From the Table 4 it is observed that the relationship is insignificant, because in the study area satisfaction does not depend on quality of house.

The regression coefficient and odd ratio for condition of sanitation is 1.420 and 4.136 (CI for OR 0.257-66.599), which implies that the sanitation have insignificant positive effects on satisfaction of the elderly people. Again, the odds ratio over sanitation is 4.136 times better satisfaction than reference category. From the Table 4 it is observed that the relationship is insignificant, because in the study area satisfaction does not depend on sanitation. The regression coefficient and odd ratio for seeing Television is 0.030 and 1.354 (CI for OR 0.15311.953) which implies that the television have positive insignificant effects on satisfaction of elderly people. Again, the odd ratio over television is 1.354 times better satisfaction than reference category.

Working status were helping family and for treatment the regression coefficient and odd ratio are -0.225 and 0.799 (CI for OR 0.059-10.785), -0.695 and 0.499 (CI for OR 0.031-1.010) respectively, which implies that 1st has insignificant negative effects and 2nd has also insignificant negative effects on satisfaction of the elderly people. Again, the odds ratio over cause of working is 0.799 and 0.499 times better satisfaction than reference category. It is observed that the relationship is insignificant, because in the study area satisfaction does not depend on working status.

Mental torture, for husband \& wife and for neibour the regression coefficient and odd ratio are -1.992 and 0.136 (CI for OR 0.006-3.370), -1.622 and 0.198 (CI for OR 0.033-12.415) respectively, which implies that mental torture 1st has insignificant negative effects and 2nd has also insignificant negative effects on satisfaction of the elderly people. 
Table 4: Odds ratios and associated inference from logistic regression models for the Satisfaction and proper management:

\begin{tabular}{|c|c|c|c|c|c|c|}
\hline \multirow{2}{*}{ Characteristic } & \multirow{2}{*}{ Coefficient $\beta$} & \multirow{2}{*}{ S.E of estimates } & \multirow{2}{*}{ Significant } & \multirow{2}{*}{ Odd ratio $\operatorname{Exp}(\beta)$} & \multicolumn{2}{|c|}{ CI of OR } \\
\hline & & & & & lower & upper \\
\hline \multicolumn{7}{|l|}{ Types of family } \\
\hline Single (RC) & ....... & ....... & $\ldots \ldots$ & 1.0 & & \\
\hline Joint & -1.976 & 1.491 & 0.185 & 0.139 & 0.007 & 2.575 \\
\hline \multicolumn{7}{|c|}{ Respondent education } \\
\hline Illiterate (RC) & $\ldots \ldots$ & $\ldots \ldots \ldots$ & $\ldots \ldots$ & 1.0 & & \\
\hline Primary & -0.646 & 0.765 & 0.399 & 0.524 & 0.117 & 2.350 \\
\hline $\begin{array}{l}\text { Secondary and } \\
\text { higher }\end{array}$ & -0.547 & 0.982 & 0.404 & 0.645 & 0.101 & 5.786 \\
\hline \multicolumn{7}{|l|}{ Quality of house } \\
\hline Brick built(RC) & $\ldots \ldots$ & $\ldots \ldots$ & $\ldots \ldots \ldots$ & 1.0 & & \\
\hline Made of mud & 0.328 & 1.276 & 0.797 & 1.389 & 0.114 & 16.921 \\
\hline \multicolumn{7}{|c|}{ Condition of sanitation } \\
\hline Brick built(RC) & $\ldots \ldots \ldots$ & ........ & ........ & 1.0 & & \\
\hline Made of mud & 1.420 & 1.418 & 0.317 & 4.136 & 0.257 & 66.599 \\
\hline \multicolumn{7}{|l|}{ Television } \\
\hline No & $\ldots \ldots$ & $\ldots \ldots$ & $\ldots \ldots$ & 1.0 & & \\
\hline Yes & 0.303 & 1.111 & 0.785 & 1.354 & 0.153 & 11.953 \\
\hline \multicolumn{7}{|l|}{ Mental torture } \\
\hline $\begin{array}{l}\text { Son and his } \\
\text { wife }(R C)\end{array}$ & $\ldots \ldots$ & $\ldots \ldots$ & $\ldots \ldots$ & 1.0 & & \\
\hline $\begin{array}{l}\text { Husband \& } \\
\text { wife }\end{array}$ & -1.992 & 1.636 & 0.223 & 0.136 & 0.006 & 3.370 \\
\hline Others & -1.622 & 2.113 & 0.443 & 0.198 & 0.003 & 12.415 \\
\hline \multicolumn{7}{|l|}{ Who take care } \\
\hline Son $(\mathrm{RC})$ & $\ldots \ldots$ & $\ldots \ldots$ & $\ldots \ldots$ & 1.0 & & \\
\hline Daughter & 0.400 & 1.375 & 0.771 & 1.491 & 0.101 & 22.072 \\
\hline Others & 0.522 & 1.119 & 0.641 & 1.685 & 0.188 & 15.098 \\
\hline \multicolumn{7}{|c|}{ Present health condition } \\
\hline Healthy (RC) & ...... & ...... & $\ldots \ldots$ & 1.0 & & \\
\hline Fairly healthy & 0.882 & 0.807 & 0.274 & 2.415 & 0.497 & 11.737 \\
\hline Unhealthy & 0.976 & 0.324 & 0.556 & 2.675 & 0.369 & 13.008 \\
\hline \multicolumn{7}{|c|}{ Serious operation } \\
\hline No (RC) & $\ldots \ldots$ & ....... & $\ldots \ldots$ & 1.0 & & \\
\hline Yes & -2.133 & 0.979 & 0.029 & 0.118 & 0.017 & 0.807 \\
\hline
\end{tabular}

\begin{tabular}{|c|c|c|c|}
\hline Step & -2 Log likelihood & Cox \& Snell R Square & Nagelkerke R Square \\
\hline 1 & $50.102^{\mathrm{a}}$ & .528 & .819 \\
\hline
\end{tabular}

a. Estimation terminated at iteration number 9 because parameter estimates changed by less than 001.

Again, the odds ratio over mental torture is 0.136 and 0.198 times better satisfaction than reference category. Present health condition, for fairly healthy and for unhealthy the regression coefficient and odd ratio are 0.882 and 2.415 (CI for OR 0.497-11.737), 0.976 and 2.675 (CI for OR 0.369-13.008) respectively, which implies that 1st has insignificant positive effects and 2nd has also insignificant positive effects on satisfaction of the elderly people. Again, the odds ratio over present health condition is 2.415 and 2.675 times better satisfaction than reference category. Serious operation, the regression coefficient and odd 
ratio is -2.133 and 0.118 (CI for OR 0.017-0.807), which implies that the serious operation have significant negative effects on satisfaction of the elderly people because in my study area there a relationship between serious operation and satisfaction. Again, the odds ratio over serious operation is 0.118 times better satisfaction than reference category.

\section{CONCLUSION}

There are quite a good number of vulnerable older persons whose families are no longer able to offer support or who have not family. These groups of older persons are possesses the following attributes: - destitute, low income, minorities, displaced and disabled with long term medical conditions. The government should identify and assess the size of these groups and the extent to which assistance is required. The older persons not only receive support and care from the family member' children their kin's, but also render care and support to the family member such as financial help and care to grand children. The overall level of health of older persons is not good. They are prone to age related disease. They proper medicine to maintain their good health. Maintenance of good health can be achieved through proper nutrition, yearly diagnosis, preventive care, and health life style, including harmonious family life, health and family education and social participation. Not only physical health but also mental and emotional health of older persons is equally important for their well-being. Health education program should be introduced for healthy aging that will help understanding and create awareness about the health problems among the elderly and adoption of a healthy life style. The elderly should be given nutritional advice to minimize dietary deficiency imbalances. In Bangladeshi society older persons are enormously respected and valued. They remain active in a variety of activities that have significance bearing on the cultural, social and economic life a country 'and society. They have a significance presence in both formal and informal sectors. So, the government should take necessary steps of the well fare for elderly people side by side mass education and awareness should be increased about the duty towards elderly people.

\section{REFERENCES}

Abedin, S. (1996). "Ageing in SAARC Countries-Issues and Perspective", Proceeding of the International Seminar on Ageing SAARC Countries, 18-19 October, 1996, pp.29-37.

Bangladesh Bureau of Statistics (BBS, 2011) "Population and Housing Census Preliminary Report 2011", Dhaka, Bangladesh.

BBS (Bangladesh Bureau of Statistics) (2002) Population Census 2001: Preliminary Report, Dhaka: BBS, Planning Divission, Ministry of Planning, Government of Bangladesh.

Biswas, B., Kabir, Z. N., Jon Nilsson and Shahadu (2006) Dynamics of Health care Seeking Behaviour of Elderly People in Rural Bangladesh (PP, 70-72).

Cain, Mead. T. (1991). "The Activities of the Rural Elderly in Rural Bangladesh", Population Studies.

Christakis, N.A., Ware, N.C. and Kleinman, A. (1994) Illness of Behavior and the Health Transition in the Developing World. In Chen, L.C., Kleinman, A. and Ware, N.C. (ends) Health and Social Change in International Perspective. Harvard Series on Population and International Health, pp.275-302.

Christman, N. (1977) The Health Seeking Process, Culture, Medicine and Psychiatry 1(4): 1357-1368.

Datta, A. (2010) "Greying Citizenship: The Situation of the Older Persons in India" Indian Journal of Gerontology. (PP. 285-288).

ESCAP (1981). Population of Bangladesh, country Monograph Series no.-8, Economic and Social Commission for Asia-Pacific, Bangkok, Thailand. 
Hossain S. M. I, Population Council, Dhaka, Bangladesh, House \# 21, Road \# 118, Gulshan, Dhaka, Bangladesh, 8821227,8826657, drsharif@popcouncil.bangla.net and Ubaidur Rob, Population Council, Dhaka, Bangladesh, House \# 21, Road \#118, Gulshan, Dhaka, Bangladesh.

Kabir and Humayun M. (1995). "The ageing and Aged in Bangladesh", Paper presented at the Fifth National Statistics Conference of the Bangladesh Association, 27-28 January, 1995, Dhaka.

Kabir, M. and Humayun, M. (1994) "Local Level of Policy Development to Deal the Consequence of Population Ageing in Bangladesh", ESCAP, UN, New York, Asian Population Studies Series.

Kabir, M. and Uddin, M. M. (1987). "Fertility Transitions in Bangladesh, Trend and Differential" Demographic Note Book, Asia-Pacific Population Journal, 2(4), ESCAP Thailand: Bangkok.

Monograph on Ageing, 2: 1-20, Department of Statistics, Rajshahi University, Bangladesh.

Singh, T., Singh, A. and Avasthi, A. Pattern of quality of Life of Long-Term Care for the Bedridden Patients in Chandigarh, North India. The International Journal of Geriatrics and Gerontology 2012.

Stong and Michael A. (1992). "The Health of Adults in Developing World: The View from Bangladesh", Adult Mortality Forum, World Bank Publication.

Sultana, T. (BDRC, 2011) Expectations, Realities, Coping Strategies of Elderly People in a Village of Bangladesh.

Tareque, M.I. (2011) Determinants of Living Arrangement, Health Status and Abuse among Elderly People: A Study of Rural Naogaon District, Bangladesh (PP-162-172).

Uddin, M.T., Chowwdhury, M.A.I., M., Islam, M.N. and Uddin, B. (2010) Status of Elderly People of Bangladesh: Health Perspective (PP-185).

World Population Prospects (WPP-1998). The 1998 Revision, Vol. II=Sex and Age. Satter, M. A. (1994). "Ageing of the Population of Bangladesh and Its Policy Implication",

Publish Online and Print Version Both

Article DOI: $\underline{\text { https://doi.org/10.18034/ajhal.v8i1.538 }}$

Online Archive: https://i-proclaim.my/journals/index.php/ajhal/issue/archive 